\title{
Direct measurement of transit time in the stomachs and intestine of dairy cows
}

\author{
JL Peyraud, M Mambrini \\ INRA, Station de Recherches sur la Vache Laitière, \\ St-Gilles, 35590 L'Hermitage, France
}

This study was undertaken to obtain direct estimation of the time required for comminution and transit of particles in the digestive tract of dairy cows.

Four rumen and duodenal fistulated cows in mid lactation were fed a hay/concentrate diet $(50 / 50)$ twice daily (16.3 kg DMI). Concentrate (CO) was labelled with dysprosium, and long hay (LH) with thullium (Peyraud et al, 1989). One part of hay was also labelled with ytterbium and ground through a 2-mm screen (GH). Faecal particles (FP) were collected for $24 \mathrm{~h}$ and labelled with europium. LH $(0.80 \mathrm{~kg})$ and $\mathrm{CO}(0.50 \mathrm{~kg})$ were offered before the morning meal. Two $\mathrm{h}$ later, $\mathrm{GH}$ $(0.25 \mathrm{~kg})$ was introduced into the rumen and $4 \mathrm{~h}$ later FP $(0.03 \mathrm{~kg})$ and $250 \mathrm{ml}$ of CrEDTA were mixed with duodenal contents and introduced into the duodenum. Total faeces collection was then performed for 9 days and total retention time was calculated from the quantities of markers excreted at each collection interval. Mean values were compared with paired $t$-test.

Total mean retention time (TMRT) of LH was longer than that of $\mathrm{GH}$ which was in turn longer than that of $\mathrm{CO}$. Intestinal transit time (ITT) of FP particles and liquids (CrEDTA) were quite similar and much shorter than transit time of particles introduced into the rumen. The difference between TMRT and ITT shows that the stomach processes represent about $80 \%$ of the total retention time of forage and concentrate. Time required for comminution of particles, estimated by the difference between $\mathrm{LH}$ and $\mathrm{GH}$, was short $(5.9 \mathrm{~h}$ ) compared to the retention time of $\mathrm{LH}$ in stomachs $(41 \mathrm{~h})$ and does not appear as a limiting factor of transit. The difference between TMRT of GH and CO might be related to a faster increase in density of $\mathrm{CO}$ particles and/or a supplementary comminution time for $\mathrm{GH}$ particles. Between cows variation was great, the 2 cows with the fastest TMRT for LH (41 vs $61 \mathrm{~h}$ for the slowest ones) also had a faster TMRT of GH and CO.

Peyraud JL, Mambrini M, Rulquin H (1989) Asian Australas J Anim Sci 2 (3) 366-367

Table I. Mean retention time of particles and liquids in the digestive tract of dairy cows.

\begin{tabular}{lcccccc}
\hline & \multicolumn{3}{c}{ Total tract } & \multicolumn{2}{c}{ Intestine } \\
\hline & & $\mathrm{LH}$ & $\mathrm{GH}$ & $\mathrm{CO}$ & $\mathrm{FP}$ & CrEDTA \\
Mean retention time (h) & $51.5^{\mathrm{a}}$ & $45.6^{\mathrm{b}}$ & $40.8^{\mathrm{c}}$ & $10.4^{\mathrm{d}}$ & $11.0^{\mathrm{d}}$ \\
Standard deviation & (h) & $11.7^{\mathrm{d}}$ & 9.2 & 7.8 & 1.5 & 1.3 \\
\hline
\end{tabular}

a. b. c. d Means with different superscripts are significantly different, $P<0.05$. 